Jurnal Bisnis dan Manajemen Vol. 4 No.2, Juni 2017, p 165-171

p-ISSN : $1829-7528$

e-ISSN : 2581-1584

\title{
HUBUNGAN BAURAN PEMASARAN DENGAN KEPUASAN KONSUMEN
}

(Studi Pada Konsumen Kafe Grow Malang)

\section{Gusti Bagus Susila, Rooswidjajani, Anandhayu Mahatma Ratri}

Fakultas Ilmu Sosial dan Ilmu Politik, Universitas Merdeka Malang

Email: anandhayu.ratri@gmail.com

\begin{abstract}
Consumer satisfaction is a strategic aspect that must be created by marketers through the strategy it has set. Consumer satisfaction has a positive impact on the company's survival, because customer satisfaction can create a customer loyalty to the company or create a positive word-ofmouth relationship.

Population in this research is consumer cafe Grow Malang counted 40 respondent by using nonprobabillity sampling (saturated sampling). The method in this research is quantitative and descriptive research. Data that has met valitidas test and reliability, then through spearman rho analysis can be seen the following results; a) Product (X1) has a value of -0.57 which means having a very weak relationship with customer satisfaction, $b)$ Price (X2) has a value of 0.463 which means the relationship price with consumer satisfaction is strong enough, c) Place (X3) has a value of 0.121 , which means a place relationship with poor consumer satisfaction, d) Promotion (X4) has a value of -0.162, which means the relationship of promotion with consumer satisfaction is very weak.
\end{abstract}

\section{Keywords: Marketing Mix, Consumer Satisfaction}

\begin{abstract}
Abstrak: Kepuasan konsumen merupakan aspek strategis yang harus diciptakan oleh para pemasar melalui strategi yang telah ditetapkannya. Kepuasan konsumen berdampak positif terhadap kelangsungan hidup perusahaan tersebut, karena kepuasan konsumen dapat menciptakan suatu keloyalan konsumen pada perusahaan ataupun menciptakan hubungan dari mulut ke mulut secara positif.

Populasi dalam penelitian ini adalah konsumen kafe Grow Malang sebanyak 40 reponden dengan menggunakan non-probabillity sampling (sampling jenuh). Metode dalam penelitian ini adalah penelitian kuantitatif dan deskriptif. Data yang telah memenuhi uji valitidas dan reliabilitas, maka melalui analisis spearman rho dapat diketahui hasil sebagai berikut; a) Produk (X1) memiliki nilai sebesar -0,57 yang berarti memiliki hubungan yang sangat lemah dengan kepuasan konsumen, b) Harga (X2) memiliki nilai sebesar 0,463 yang berarti hubungan harga dengan kepuasan konsumen cukup kuat, c) Tempat (X3) memiliki nilai sebesar 0,121, yang berarti hubungan tempat dengan kepuasan kosumen lemah, d) Promosi (X4) memiliki nilai sebesar -0,162, yang berarti hubungan promosi dengan kepuasan konsumen sangat lemah.
\end{abstract}

Kata Kunci: Bauran Pemasaran, Kepuasan Konsumen

Kafe Grow merupakan kafe yang memang memiliki dasar penjualan bagaimana layaknya kafe-kafe yang ada di Indonesia yang tetap memberikan suasana budaya Indonesia itu sendiri. Kafe Grow bertempat di kota Malang, Jawa Timur khususnya di jalan Bunga Songolangit, Malang. Di kota Malang itu sendiri memiliki banyak kafe-kafe yang telah berdiri, seperti salah satunya adalah kafe Uno, Balebarong, Pujasera Terace, The Flame Cafe, Jordan Cafe, dan masih bnyak lainnya yang akan memberikan dampak persaingan bagi kafe Grow itu sendiri, oleh karena itu kafe Grow harus memiliki strategi yang tepat untuk menghadapi persaingan tersebut.

Menghadapi persaingan memang perlu adanya, karena persaingan dapat mengakibatkan kerugian bagi kafe Grow itu sendiri karena konsumen berpindah ke pesaing, dan yang lebih penting kafe Grow harus mampu mempertahankan kelangsungan hidupnya untuk melakukan aktivitas bisnisnya. Menghadapi persaingan memang cukup sulit aplagi meihat para pesaing telah memiliki nama atau brand dimata konsumen. Melihat hal tersebut juga kafe Grow harus mampu memusatkan strategi pada konsumennya itu sendiri dengan kata lain 
memberikan kepuasan pada konsumen adalah salah satu cara yang tepat untuk menghadapi persaingan tersebut.

Kepuasan konsumen memang penting adanya, karena hal tersebut sangat berdampak positif bagi kafe Grow itu sendiri, seperti meningkatnya omset penjualan dan yang lebih penting kafe Grow dapat mempertahankan kelangsungan hidup untuk jangaka waktu yang panjang, karena hal tersebut disebabkan jika konsumen merasa puas setelah apa yang didapat dari kafe Grow, konsumen akan lebih loyal atau lebih setia untuk melakukan permintaan pada kafe Grow. Selain itu juga, kepuasan konsumen dapat menyebabkan komunikasi dari mulut ke mulut yang secara baik kepada orang-orang disekitarnya, oleh sebab itu kepuasah konsumen memang sangat penting untuk menjaga aktivitas bisnis yang telah ditargetkan oleh kafe Grow itu sendiri.

Melihat bauran pemasaran merupakan salah satu alternatif strategi yang dapat menciptakan kepuasan tersebut, kafe Grow harus meningkatkan penerepan unsur-unsur dalam bauran pemasaran, seperti meningkatkan kualitas produknya, atau menetapkan harga yang terjangkau oleh konsumennya. Berdasarkan hal tersebut, kafe Grow harus mampu mengamati kebutuhan konsumen yang berkaitan dengan bauran pemasarannya, karena memang kebutuhan konsumen merupakan hal yang paling krusial yang dapat berubah-ubah. Selain itu juga, kafe Grow harus memiliki informasi keunggulan dari para pesaingnya agar dapat menjadi tolak ukur tingkat kebutuhan konsumen.

Berdasarkan masalah tersebut peneliti bertujuan untuk melakukan suatu penelitian yang berjudul Hubungan Bauran Pemasaran Dengan Kepuasan Konsumen, karena melihat pada pembahasan sembelumnya buaran pemasaran sangat berpengaruh akan terjadinya nalai kepuasan yang dimiliki oleh konsumen sehingga dapat disimpulkan bauran pemasaran memiliki hubungan yang kuat akan terjadinya kepuasan konsumen itu sendiri.

Studi penelitian ini dilakukan pada konsumen kafe Grow Malang. Peneliti memilih kafe Grow sebagai lokasi penelitian, karena perusahaan tersebut memiliki tingkat persaingan yang cukup tinggi dan bersaing dengan pesaingpesaing yang telah memiliki nama ataupun brand sehingga kafe Grow harus memiliki perhatian dibidang pemasaran baik dari bidang praktisi maupun akademisi sehingga mampu melangsungkan hidup perusahaan tersebut ditengah-tengah ketatnya situasi persaingan yang dialaminya.

\section{TINJAUAN PUSTAKA}

\section{Bauran Pemasaran}

Menurut Kotler dan Amstrong (2001:71),"Bauran pemasaran merupakan seperangkat alat pemasaran taktis dan terkontrol yang dipadukan oleh perusahaan untuk menghasilkan respon yang diinginkan pasar". Kotler (2005:17) bauran pemasaran diklarifikasikan menjadi empat dan dikenal dengan istilah 4P yang terdiri dari product, price, place, dan promotion.

\section{Product (Produk)}

Menurut Kotler dan Amstrong (2001:346), "produk adalah segala sesuatu yang dapat ditawarkan ke pasar untuk diperhatikan, diperoleh, digunakan dan dipasarkan meliputi barang-barang fisik, pengalaman, orang, tempat, property, organisasi, dan gagasan".

\section{Price (Harga)}

Menurut Kotler (2001:31), harga adalah jumlah nilai yang ditukarkan konsumen dengan mendapatkan manfaat dari memiliki atau menggunakan produk atau jasa tersebut, atau dengan kata lain harga merupakan jumlah uang yang dibebankan yang dibebankan atas suatu barang atau jasa.

\section{Place (Tempat)}

Menurut Lupiyoadi (2001:73), tempat merupakan gabungan antara lokasi dan saluran distribusi. Tempat dijadikan unsur penting dalam bauran pemasaran karena unsur ini digunakan untuk perusahaan-perusahaan yang melakukan pertukaran langsung ditempat tersebut ataupun pada saluran distribusi yang dimilikinya.

\section{Promotion (Promosi)}

Menurut Alma (2004:179), "promosi adalah suatu bentuk komunikasi pemasaran yang merupakan aktivitas pemasaran yang berusaha menyebarkan informasi, mempengaruhi/membujuk, dan mengingatkan pasar sasaran atas perusahaan dan produknya agar bersedia menerima, membeli, dan loyal pada produk yang ditawarkan perusahaan yang bersangkutan".

Kepuasan Konsumen 
Menurut Kotler, dkk (2000:52), "Kepuasan adalah tingkat perasaan seseorang setelah membandingkan kinerja atau hasil yang dia rasakan dibandingkan dengan harapannya". "Sedangkan ketidak puasan timbul apabila hasil (outcome) tidak memenuhi harapan" (Tjiptono, 2004:349).

\section{METODE}

\section{Variabel Penelitian}

Variabel Bebas (independent variable)

Variabel ini sering disebut variabel stimulus, prediktor, antecedent. Dalam bahasa Indonesia sering disebut sebagai variabel bebas. Variabel bebas merupakan variabel yang mempengaruhi atau yang menjadi sebab perubahan atau timbulnya variabel dependen (terikat) (Sugiyono, 2010:4). Variabel independen (variabel bebas) dalam penelitian ini yaitu Bauran Pemasaran (X) yang terditi dari Produk (X1), Harga (X2), Tempat (X3), Promosi (X4).

\section{Variabel Terikat (dependent varible)}

Variabel dependen sering disebut sebagai variabel output, kriteria, konsekuen. Dalam bahasa indonesia sering disebut sebagai variabel terikat. "Variabel terikat merupakan variabel yang dipengaruhi atau yang menjadi sebab akibat karena adanya variabel bebas" (Sugiyono, 2010:4). Variabel dependen (variabel terikat) dalam penelitian ini yaitu Kepuasan Konsumen (Y).

\section{Populasi dan Sampel}

Populasi yang digunakan pada penelitian ini yaitu konsumen pada Kafe Grow Malang secara kebetulan ditemui oleh peneliti di lokasi penelitian. Sedangkan teknik pengambilan sampel yaitu teknik accidental sampling menurut (Santoso, 2001) adalah teknik ini mengambil data dari siapa saja yang kebetulan bertemu dengan peneliti dapat dipergunakan sebagai sampel bila dipandang orang yang kebetulan ditemui itu cocok sebagai sumber data. Berdasarkan penentuan minimal sampel menurut ahli di atas, maka pengambilan sampel dalam penelitian ini dengan responden yang terpilih adalah pengunjung yang mudah ditemui dan dimintai menjawab kuesioner, yaitu sebanyak 40 responden melihat dari populasi yang berada pada tempat penelitian.

\section{Teknik Analisis Data}

Penggunaan analisis pada penelitian ini menggunakan analisis korelasi, karena penelitian ini menganalisis tentang hubungan yang dimiliki dari vairbel bebas dengan variabel terikat. Analisis korelasi merupakan ukuran numeris yang dapat diinterprestasikan sebagai derajat keeratan hubungan linear, dengan tujuan untuk mengetahui apakah terdapat hubungan antara dua variabel atau lebih, bagaimana arah hubungan dan berapa besar koefisien hubungan (Rochaety, et al, 2007:124).

Sedangkan pada penelitian ini menggunakan koralasi spearman yang digunakan untuk mengukur hubungan antara dua variabel dengan berskala ordinal (nonparametric). Ketentuan korelasi yaitu jika korelasi menghasilkan angka positif maka hubungan kedua bersifat searah, dan jika menghasilkan angka negative artinya hubungan kedua variabel tidak searah (Rochaety, et al, 2007:125). Angka korelasi berkisaran antara (1) dengan 1, jika angka mendekati 1 maka angka hubungan kedua variabel semakin kuat. Jika korelasi mendekati (-1) maka hubungan kedua variabel semakin lemah.

\section{Lokasi Penelitian}

Lokasi penelitian ini yaitu di Jl. Bunga Songolangit 56 Malang.

\section{HASIL DAN PEMBAHASAN \\ Analisis Korelasi Spearman Rho}

Tabel 1 Analisis Korelasi Spearman Rho pada Produk (X1)

\begin{tabular}{|ll|l|l|}
\hline & \multicolumn{3}{|c|}{ Correlations } \\
\hline & & produk & $\begin{array}{l}\text { kepuasan } \\
\text { konsumen }\end{array}$ \\
\hline Produk & Correlation & 1.000 & .057 \\
& Coefficient & & \\
& Sig. (2-tailed) & & .728 \\
$\mathrm{~N}$ & 40 & 40 \\
\hline
\end{tabular}




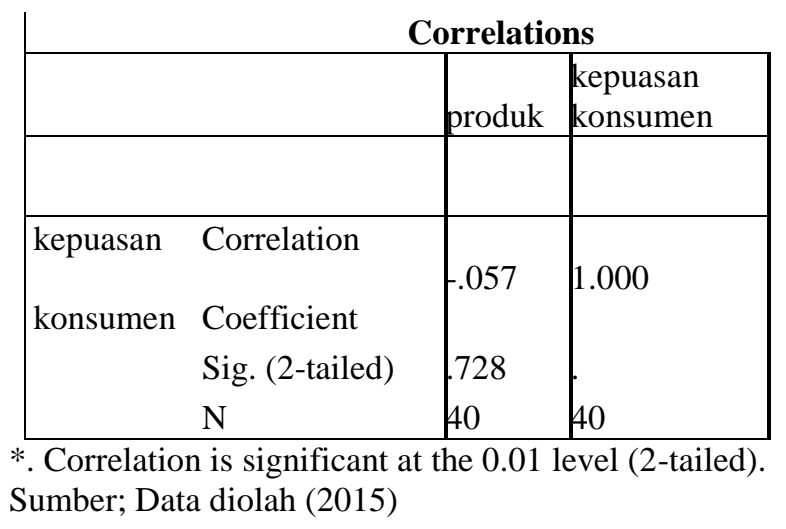

Hasil pada tabel diatas dapat diketahui bahwa hubungan yang dimiliki produk dengan kepuasan konsumen tidak searah yang memiliki nilai sebesar -0,57. Berdasarkan nilai tersebut juga dapat disimpulkan hubungan yang dimiliki produk dengan kepuasan konsumen sangat lemah.

Tabel 2 Analisis Korelasi Spearman Rho pada Harga (X2)

\section{Correlations}

\begin{tabular}{|c|c|c|c|}
\hline Harga & $\begin{array}{l}\text { Correlation } \\
\text { Coefficient } \\
\text { Sig. (2-tailed) } \\
\text { N }\end{array}$ & $\begin{array}{l}\text { harga } \\
1.000\end{array}$ & $\begin{array}{l}\text { kepuasan } \\
\text { konsumen } \\
463^{* *} \\
.003 \\
40\end{array}$ \\
\hline $\begin{array}{l}\text { kepuasan } \\
\text { konsumen }\end{array}$ & $\begin{array}{l}\text { Correlation } \\
\text { Coefficient } \\
\text { Sig. (2-tailed) } \\
\text { N }\end{array}$ & $\begin{array}{l}.463^{* *} \\
.003 \\
40\end{array}$ & 40 \\
\hline
\end{tabular}

*. Correlation is significant at the 0.01 level (2-tailed). Sumber; Data diolah (2015)

Hasil pada tabel diatas dapat diketahui bahwa hubungan yang dimiliki produk dengan kepuasan konsumen searah yang memiliki nilai sebesar 0,463. Berdasarkan nilai tersebut juga dapat disimpulkan

Tabel 3 Analisis Korelasi Spearman Rho pada Tempat (X3)

\begin{tabular}{ll|l|l|}
\hline & \multicolumn{3}{c}{ Correlations } \\
\hline Tempat & Correlation & tempat & $\begin{array}{l}\text { kepuasan } \\
\text { konsumen }\end{array}$ \\
& Coefficient & 1.000 & 121 \\
& Sig. (2-tailed) & & 455 \\
& $\mathrm{~N}$ & 40 & 40 \\
\hline kepuasan & Correlation & & \\
konsumen & Coefficient & 121 & 1.000 \\
& Sig. (2-tailed) & 455 &. \\
& $\mathrm{~N}$ & 40 & 40 \\
\hline
\end{tabular}

*. Correlation is significant at the 0.01 level (2-tailed). Sumber; Data diolah (2015) 
Hasil pada tabel diatas dapat diketahui bahwa hubungan yang dimiliki produk dengan kepuasan konsumen searah yang memiliki nilai sebesar 0,121 . Berdasarkan nilai tersebut juga dapat disimpulkan bahwa hubungan produk dengan kepuasan konsumen lemah.

\section{Promosi (X4)}

\begin{tabular}{|c|c|c|c|}
\hline & \multicolumn{3}{|c|}{ Correlations } \\
\hline & & Promosi & $\begin{array}{l}\text { Kepuasan } \\
\text { Konsumen }\end{array}$ \\
\hline Promosi & $\begin{array}{l}\text { Correlation } \\
\text { Coefficient } \\
\text { Sig. (2-tailed) } \\
\text { N }\end{array}$ & $\begin{array}{l}1.000 \\
40\end{array}$ & $\begin{array}{l}.162 \\
318 \\
40\end{array}$ \\
\hline $\begin{array}{l}\text { kepuasan } \\
\text { konsumen }\end{array}$ & $\begin{array}{l}\text { Correlation } \\
\text { Coefficient } \\
\text { Sig. (2-tailed) } \\
\text { N }\end{array}$ & $\begin{array}{l}.162 \\
.318 \\
40\end{array}$ & $\begin{array}{l}1.000 \\
40\end{array}$ \\
\hline
\end{tabular}

Hasil pada tabel diatas dapat diketahui bahwa hubungan yang dimiliki produk dengan kepuasan konsumen tidak searah yang memiliki nilai sebesar $-0,162$. Berdasarkan nilai tersebut juga dapat disimpulkan bahwa hubungan produk dengan kepuasan konsumen sangat lemah.

\section{Pembahasan}

Pada hasil penelitian dapat jelaskan hasil penelitian tersebut bahwa secara parsial produk, tempat dan promosi pada Kafe Grow tidak memiliki pengaruh terhadap kepuasan konsumennya, sedangkan harga pada Kafe Grow memiliki pengaruh terhadap kepuasan konsumennya. Selain itu penelitian ini juga memiliki hasil bahwa unsur-unsur bauran pemasaran yang terdiri dari produk, harga, tempat, saluran distribus secara simultan atau bersama-sama memiliki pengaruh terhadap kepuasan konsumen pada kafe Grow.

Produk, tempat, promosi tidak memiliki peengaruh karena memang melihat jawaban yang memiliki rata-rata yang menunjukkan responden yang kurang setuju terhadap unsurunsur tersebut yang dimiliki oleh Kafe Grow itu sendiri. Produk sangat penting dalam perusahaan, akan tetapi produk dapat berubah menjadi tidak penting dimata konsumen karena suatu hal misalkan tingginya harga, atau banyaknya produk sejenis dari pesaing. Berdasarkan hal tersebut dapat diketahui bahwa hubugan produk dengan Kepuasan konsu- mennya pada kafe grow sangat lemah. Hasil tersebut bertentangan dengan hasil penilitan yang telah dilakukan oleh Wowor (2012) yang memiliki hasil bahwa produk berpengaruh terhadap kepuasan konsumen Pengguna Mobil Toyota Avanza Veloz PT Toyota Hasjrat Abadi Manado. Selain itu juga, hasil tersebut didukung melalui hasil pada deskriptif penelitian ini yang memiliki hasil bahwa skor rata-rata (mean) variabel produk yang menyatakan bahwa memiliki respon yang negatif atau tidak setuju.

Harga memang sangat penting adanya karena nilai suatu produk diukur melalui harga yang telah ditetapkan oleh produsen sehingga harga menjadi pertimbangan konsumen untuk melakukan pembelian. Pertimbangan tersebut merupakan langkah awal sebelum terjadinya pertukaran, pada dasarnya kepuasan dihasilkan setelah pertukaran tersebut dilakukan sehingga saat mengkonsumsi produk yang telah didapatnya kemudian konsumen membandingkan dengan tingkat nilai yang telah ditukarkan jika memiliki hasil yang baik konsumen akan merasa puas dan sebaliknya, oleh karena itu faktor harga merupakan faktor yang paling penting untuk menciptakan rasa puas yang dimiliki oleh konsumennya dan harga memiliki hubungan yang cukup kuat terhadap. Hal tersebut sesuai dengan pernyataan yang dikemukakan oleh Wanardi (1989:171) bahwa harga suatu produk merupakan ukuran besar kecilnya nilai kepuasan seseorang terhadap yang dibelinya. Selain itu, Hasil tersebut juga 
didukung dengan penelitian yang dilakukan oleh Tedjosaputro yang memiliki hasil varaibel harga berada pada daerah penolakan Ho, yang berarti harga memang memiliki kaitan akan terjadinya kepuasan konsumen Kantor Notaris/PPAT Dr. Liliana Tedjosaputro, SH., MH.

Selain itu juga, tempat menjadi tolak ukur ketika suatu perusahaan yang melakukan penjualan atau pertukaran langsung dimana produk tersebut ditawarkan, hal ini memiliki penilaian baik dari segi keleluasan konsumen dalam melakukan proses penggunaan produk, baik dari lokasi makan maupun parkir sehingga konsumen menjadi nyaman. Munculnya kenyamanan tersebut akan mengakibatkan suatu kepuasan terhadap konsumen. Melihat bahwa unsur tempat kafe Grow kurang menarik respon yang positif dari konsumennya, sehingga hubungan tempat dengan kepuasan konsumen lemah.

Promosi juga salah satu unsur yang memiliki hubungan tidak searah dan sangat lemah dengan kepuasan konsumen kafe Grow Malang, hal tersebut didukung juga bahwa ratarata penilaian yang dilakukan oleh konsumennya menunjukkan respon yang negatif terhadap unsur promosi pada kafe Grow yang memiliki nilai rata-rata skor jawaban pada posisi tidak setuju. Hasil penelitian ini didukung oleh penelitian yang dilakukan Wowor (2012) yang memiliki hasil, bahwa unsur promosi tidak berpengaruh secara parsian terhadap kepuasan Konsumen Mobil Toyota Avanza Veloz PT. Hasjrat Abadi Manado.

\section{KESIMPULAN DAN SARAN \\ Kesimpulan}

1. Harga merupakan unsur bauran pemasaran memiliki hubungan cukup kuat dengan kepuasan konsumen pada Kafe Grow Malang.

2. Tempat memiliki hubungan yang lemah dengan kepuasan konsumen pada Kafe Grow Malang.

3. Produk dan Promosi memiliki hubungan yang sangat lemah dengan kepuasan konsumen pada Kafe Grow Malang.

\section{Saran}

1. Produk kafe Grow perlu ditingkatkan, karena memang para konsumen memerlukan produk-produk yang baik dari perusahaan. Seperti halnya, makanan yang memiliki cita rasa yang lezat/enak dan sehat untuk dikonsumsi, memiliki fasilitas ruangan yang menarik dan bersih agar konsumen dapat dengan nyaman mengkonsumsi makanan maupun minuman yang disediakan.

2. Tempat perlu diperhatikann seperti halnya keluasan lahan parkir yang disediakan oleh kafe Grow agar konsumen merasa nyaman, serta meningkatkan saluran distribusi seperti halnya memberikan kemudahan kepada konsumen dalam pemesanan makanan dan minuman pada kafe Grow atau memberikan pelayanan yang cepat dalam memenuhi pemesanan pada konsumennya.

3. Promosi yang dilakukan harus memiliki daya tarik yang mampu menarik perhatian dari para konsumennya seperti halnya memberikan potongan harga diakhir bulan ataupun promosi yang memberikan informasi sabagai landasan konsumen dalam melakukan penawaran seperti memberikan informasi kepada konsumen tetang makanan dan minuman yang beda dari yang lain dan memiliki harga yang terjangkau.

\section{DAFTAR PUSTAKA}

Alma, Buchari, 2007, Manajemen Pemasaran dan Pemasaran Jasa, Bandung: Alfabeta.

Hurriyati, Ratih, 2010, Bauran Pemasaran Jasa, Cetakan Pertama, Alfabeta, Bandung.

Kotler, Philip et al, 2000, Manajemen Pemasaran, Jakarta: Salemba Empat. , 2001, Manejemen Pemasaran, Jakarta: Salemba Empat. , 2005, Manejemen Pemasaran, Jakarta: Salemba Empat.

Lupiyoadi, Rambat, 2001, Manajemen Pemasaran Jasa, Edisi I, Jakarta: Salemba Empat.

2006, Manajemen Pemasaran Jasa, Edisi II, Salemba Empat, Jakarta.

Payne, Adrian, 1993, Pemasaran Jasa, Edisi I, Yogyakarta: Andi.

Porter, Michael, E, 1991, Strategi Bersaing, Cetakan Keempat, Jakarta: Erlangga.

Rangkuti, Freddy, 2002, Riset Pemasaran, Cetakan Kelima, Jakarta: Gramedia

Sangarimbun dan Sofian Effendi, 2006, Metode Penelitian Survai, Cetakan Kedelapanbelas. Jakarta Barat: LP3ES

Sanusi, Anwar, 2011, Metode Penelitian Bisnis, Cetakan Kedua, Jakarta: Salemba Empat.

Simamora, Bilson, 2003, Memenangkan Pasar, Cetakan Kedua, Gramedia, Jakarta. 
Stanton, J, William, 1985, Prinsip-prinsip Pemasaran, Edisi VII, Erlangga, Jakarta.

Supranto, J, 1997, Pengukuran Kepuasan Pelanggan, Cetakan Pertama. Jakarta: PT Rineka Cipta.

Sugiyono, 2011, Statistika Untuk Penelitian, Bandung: Alfabeta.

Swasta, Basu, 2000, Azaz-azaz Marketing, Edisi
I, Yogyakarta: BPFE. 2002, Manajemen Pemasaran, Yogyakarta: Liberty.

Tjiptono, Fandy, 2005, Pemasaran Jasa, Cetakan Pertama, Malang: Bayumedia Publishing.

Tjiptono, Fandy, 2004, Total Quality service. Edisi IV, Yogyakarta: ANDI 